UNIVERSIDADE ESTADUAL DE FEIRA DE SANTANA

Autorizada pelo Decreto Federal $n^{\circ} 77.496$ de 27/04/76

Recredenciamento pelo Decreto $n^{\circ} 17.228$ de 25/11/2016

PPPG

PRÓ-REITORIA DE PESQUISA E PÓS-GRADUAÇÃO

COORDENAÇÃO DE INICIAÇÃO CIENTÍFICA

XXIII SEMINÁRIO DE INICIACCÃO CIENTÍFICA DA UEFS

SEMANA NACIONAL DE CIENTÍFICA E TECNOLÓGICA - 2019

\title{
CONDUTIVIDADE HIDRÁULICA DO SOLO CENTRO INDUSTRIAL DO SUBAÉ EM DIFERENTES ESTAODS DE COMPACTAÇÃO, COM FLUXO DE ÁGUA E DIESEL
}

\author{
$\underline{\text { Maike Matias Dias }}{ }^{1}$ e Riseuda Pereira de Sousa ${ }^{2}$ \\ 1.Bolsista PROBIC, Graduando em Engenharia Civil, Universidade Estadual de Feira de Santana, e-mail: \\ maikematias@hotmail.br \\ 2.Orientadora, Departamento de Tecnologia, Universidade Estadual de Feira de Santana, e-mail: \\ riseuda.sousa@gmail.com.br
}

PALAVRAS-CHAVE: coeficiente de permeabilidade a água e ao diesel; compactação.

\section{INTRODUÇÃO}

A contaminação de solos por derivados de petróleos, rejeitos de indústrias químicas e de esgotos domésticos são responsáveis por inúmeros problemas ambientais. $\mathrm{O}$ fluxo destes produtos na superfície do solo pode resultar numa migração para o lençol freático ocasionando a contaminação dos aquíferos, fonte de água potável para população.

Na tentativa de preservação dos recursos hídricos estudos intensos são realizados por grupos como os da Área de Geotecnia Ambiental/Mecânica dos Solos Não Saturados, que busca através da análise comportamental do meio percolante e de ações mitigadoras evitar que este contaminante, uma vez disposto no meio ambiente, atinja o lençol freático. A realização deste tipo de estudo requer conhecimento não só das características físicas do solo e do fluido, mas também das características hidráulica do meio percolante. Uma destas propriedades de uma importância é o coeficiente permeabilidade, também denominado de condutividade hidráulica, a qual devido, tanto a dependência apresenta em relação a estrutura do solo, como a relevância nos estudos de fluxo em meios porosos e ambientes impactados por contaminantes de diferentes naturezas, precisa ser quantificada. Como o projeto que abriga esta pesquisa visa o estudo de contaminação do solo do Centro Industrial de Subaé (CIA), neste trabalho foi estudado o coeficiente de permeabilidade que o do solo do CIS, em diferentes estados de compactação, apresenta à água e ao diesel.

\section{MATERIAL E MÉTODOS}

A caracterização física do material, composta de: peso específico dos grãos, granulometria conjunta, compactação, limite de liquidez e limite de plasticidade, foram realizadas no laboratório de Mecânica dos Solos da Universidade Estadual de Feira de Santana (UEFS), seguindo as normas da ABNT - NBR 6457 (1986). 6459 (1984), 6508 (1984), 7180 (1984), 7181 (1984), 7182 (1986), 14545 (2000). 
A caracterização química e mineralógica composta de: análises de natureza qualitativa e quantitativa das espécies químicas presentes no solo forma realizadas por meio da fluorescência de raios-X, no Laboratório de Geotecnia Ambiental da Universidade Federal da Bahia (GEOAMB - UFBA) utilizando um analisador de Fluorescência de Raio X portátil (X-MET 7500, Oxford Instruments, USA), empregando-se o método de análise Soil LE FP, por 15 segundos. Enquanto a presença dos argilominerais foi determinado por difração de raio-x, no Laboratório de Ensaios em Durabilidade dos Materiais (LEDma) da UFBA, utilizando um difratômetro de raio-X, (D2 Phaser, Bruker, USA) com tubo de cobre $(\lambda=1,5418 \mathrm{~A})$, velocidade de $2 \% \mathrm{~min}$, rotação de $15 \%$ min, potência de $30 \mathrm{KV}$ e corrente de $10 \mathrm{~mA}$.

A caracterização dos fluidos utilizados (água coletada das torneiras da UEFS, proveniente de poços artesianos e óleo diesel BS 500, adquirida no Posto Contorno LTDA-Petrobras) envolveu as determinações de: massa específica, utilizando picnômetros; viscosidade, utilizado viscosímetro Cannon Faske e $\mathrm{pH}$ utilizando pHmetro.

Para determinação dos coeficientes de permeabilidade do solo à água e ao óleo diesel foram montados, no Laboratório de Fluidos e Hidráulica/LABOTEC/UEFS, dois sistemas cujos croquis e imagens dos permeâmetros são vistos nas Figuras 1 e 2. Nestes sistemas constavam permeâmetros de paredes rígidas, confeccionados no modelo de Cardoso (2011) e Sousa (2012), onde os solos foram compactado com densidades nas condições de Proctor Normal e de campo, seguindo o procedimento adotado em Sousa (2012), e submetido a ensaios de permeabilidade à carga variável utilizando água e óleo diesel como fluido percolante:

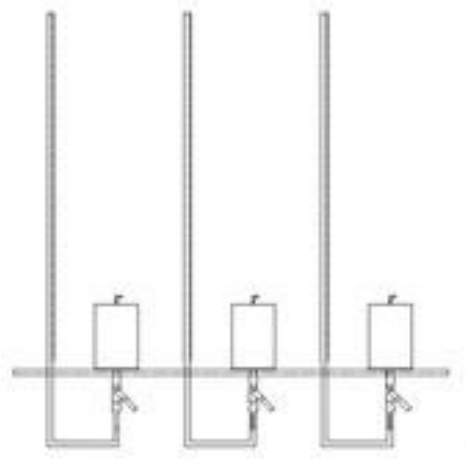

A

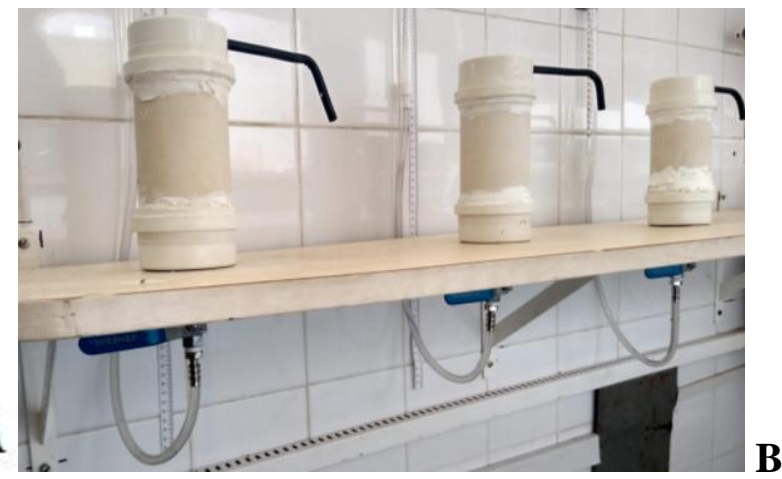

Figura 1- Ensaio de permeabilidade à água: A-croqui do sistema e B-permeâmetros.
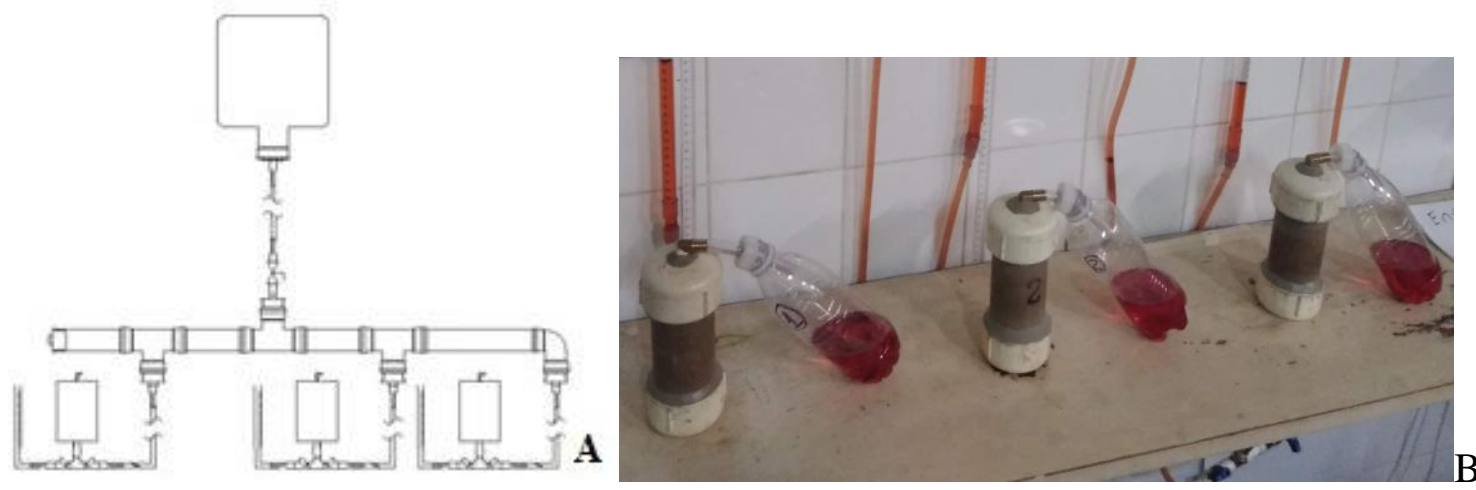

Figura 2- Ensaio de permeabilidade ao diesel: A-croqui do sistema e B-permeâmetros. 


\section{RESULTADOS E DISCUSSÃO}

O solo do CIS é uma areia argilosa de alta plasticidade (21\%), que traz na sua composição física, pedregulho $(3,6 \%)$, areia grossa $(9,9 \%)$, areia média $(21,5)$, areia fina $(17 \%)$, silte $(4,5 \%)$ e argila $(43,5 \%)$; A presença de altos teores de Sílica $(63,78 \%)$ e Alumínio (32,7), substâncias que são responsáveis pela presença do mineral quartzo e os argilominerais haloisita e caulinita. Já para os fluidos utilizados foram obtidos os valores vistos na Tabela1.

Tabela 1-Caracteristicas Química do solo

\begin{tabular}{cccccc}
\hline Fluido & \multicolumn{5}{c}{ Propriedade do Fluido à $20^{\circ} \mathrm{C}$} \\
\cline { 2 - 6 } & $\begin{array}{c}\text { Massa } \\
\text { específica } \\
\mathrm{gcm}^{-3}\end{array}$ & Viscosidade & $\mathrm{pH}$ & $\begin{array}{c}\text { Teor de água por } \\
\text { Karl Fischer }\end{array}$ & $\begin{array}{c}\text { Constante } \\
\text { dielétrica } \\
\mathrm{mgkg}^{-1}\end{array}$ \\
$\begin{array}{cccc}(-) \\
\text { Água }\end{array}$ & 1,01 & $4,87 \times 10-3$ & 6,4 & - & $80,08^{* *}$ \\
Óleo Diesel & 0,89 & $4,40 \times 10-2$ & 6,3 & $247,8 *$ & $2,13^{* *}$ \\
\hline *Dado da tabela do fornecedor; Dado de Oliveira a $\mathrm{T}=20^{\circ} \mathrm{C}$ de Oliveira $(2001)$
\end{tabular}

A Tabela 2 apresenta os resultados dos ensaios de permeabilidade água e óleo diesel e os índices pós ensaios obtidos.

Tabela 2- Coeficiente de permeabilidade a água e ao diesel e os índices após ensaios

\begin{tabular}{|c|c|c|c|c|c|c|c|}
\hline \multirow[b]{2}{*}{ Fluido } & \multirow{2}{*}{$\begin{array}{l}\text { Condições de } \\
\text { compactação }\end{array}$} & \multirow[b]{2}{*}{$\begin{array}{c}\rho_{d} \\
\text { por } P\end{array}$} & \multirow{2}{*}{$\begin{array}{c}\text { № do P/ } \\
\text { № de } E\end{array}$} & \multicolumn{3}{|c|}{ Coeficiente de Permeabilidade (K) } & \multirow[b]{2}{*}{$\rho_{\mathrm{d}}$ médio } \\
\hline & & & & $\begin{array}{c}\text { Média de } \\
\text { K por } \mathrm{P}\end{array}$ & $\mathrm{K}$ médio & DP & \\
\hline \multirow{4}{*}{ Água } & & $\mathrm{gcm}^{-3}$ & $(-)$ & $\mathrm{cms}^{-1}$ & $\mathrm{cms}^{-1}$ & $(-)$ & $\mathrm{gcm}^{-3}$ \\
\hline & Densidade de & 1,50 & $01 / 04$ & $8,73 \mathrm{E}-05$ & & $4,03 \mathrm{E}-06$ & \\
\hline & campo na umidade & 1,68 & $02 / 04$ & $5,41 \mathrm{E}-05$ & $8,61 \mathrm{E}-05$ & $5,24 \mathrm{E}-06$ & 1,63 \\
\hline & higroscópica & 1,71 & $03 / 04$ & $1,17 \mathrm{E}-04$ & & $2,57 \mathrm{E}-05$ & \\
\hline \multirow{3}{*}{ Água } & Densidade na & 1,75 & $02 / 01$ & $2,85 \mathrm{E}-06$ & & - & \\
\hline & umidade ótima, & 1,78 & $03 / 03$ & $1,67 \mathrm{E}-07$ & $1,34 \mathrm{E}-06$ & $1,31 \mathrm{E}-06$ & 1,78 \\
\hline & Proctor Normal & 1,82 & $01 / 01$ & $1,01 \mathrm{E}-06$ & & - & \\
\hline \multirow{3}{*}{ Diesel } & Densidade de & 1,73 & $01 / 04$ & $1,88 \mathrm{E}-05$ & & $1,22 \mathrm{E}-05$ & \\
\hline & campo na umidade & 1,80 & $02 / 04$ & $2,10 \mathrm{E}-05$ & $2,31 \mathrm{E}-05$ & $1,30 \mathrm{E}-05$ & 1,75 \\
\hline & higroscópica & 1,73 & $03 / 04$ & $2,95 \mathrm{E}-05$ & & $1,56 \mathrm{E}-05$ & \\
\hline \multirow{3}{*}{ Diesel } & Densidade na & $1,87 *$ & $01 / 01$ & $2,53 \mathrm{E}-06$ & & - & \\
\hline & umidade ótima, & $2,06 *$ & $02 / 01$ & $4,11 \mathrm{E}-07$ & $1,00 \mathrm{E}-06$ & - & 2,01 \\
\hline & Proctor Normal & $2,11 *$ & 03/01 & $6,02 \mathrm{E}-08$ & & - & \\
\hline
\end{tabular}

Legenda: $\rho_{\mathrm{d}}=$ Massa específica seca; $\mathrm{P}=$ permeâmetro; $\mathrm{E}=$ Ensaio; $\mathrm{DP}=$ Desvio padrão; *=na condição de compactação

Os ensaios de permeabilidade mostraram que nas condições de campo o solo apresenta uma permeabilidade a água de $8,61 \mathrm{E}-05 \mathrm{~cm} / \mathrm{s}$ e nas condições de Proctor Normal o valor é 1,34E-06 cm/s. Já para os ensaios com óleo diesel o valor obtido nas condições de campo foi de 2,31E-05 cm/s, e nas condições de Proctor Normal, e 1,00E-06 cm/s, para os ensaios realizados. Valores previsto para solo com teores de argila e silte. 
Conforme esperado amostras do solo compactados com a densidade de campo apresentaram coeficiente de permeabilidade maior (ordem de grandeza na faixa de 10E05), que os solos compactados nas condições de Proctor Normal, (ordem de grandeza na faixa de 10E-06). Apesar da água ser um fluido menos viscoso o coeficiente de permeabilidade se mostrou apenas levemente maior que do óleo diesel (fluido mais viscoso). Isto deve-se a alta afinidade da água pelos argilominerais presentes no solo (caulinita e haloisita no teor total de 43,5\%) que diante da sua polarização molecular lhe proporciona uma constante dielétrica próxima de 80 , ao passo que a natureza apolar do diesel the concede uma constante dielétrica de 2,13. Os resultados indicam a viabilidade dos sistemas e permeâmetros montados para ensaios de permeabilidade dos fluidos.

\section{CONSIDERAÇÕES FINAIS}

Os resultados alcançados com valores na ordem de 10E-05 a 10E-06 para os coeficiente de permeabilidade nas condições de densidade de campo e de Proctor Normal, para água e óleo diesel, estão condizente com as características do solo estudado, um arenoargiloso que apresenta em sua composição 43,5\% de argila; 4,5\% de silte; $17 \%$ de areia fina $21,5 \%$ de areia média; $9,9 \%$ de areia grossa e 3,6\% de pedregulho.

Por seu turno, a proximidade dos valores obtido para o coeficiente de permeabilidade à água (fluido menos viscoso) e ao diesel(fluido mais viscoso) tanto para o solo compactado nas condições de campo (água 8,61E-05 cm/s e diesel 2,31E-05 cm/s) como para o solo compactado nas condições de Proctor Normal (água 1,34E-06 cm/s e diesel 1,00E-06 cm/s) deve-se a presença do argilominerais caulinita e haloisita (teor total de 43,5\%) e da polaridade da molécula da água, que tem o seu fluxo reduzido diante do elevado valor da constante dielétrica 80 ao contrário do diesel um fluido apolar cuja constante dielétrica é de 2,13.

\section{REFERÊNCIAS}

ABNT: NBR 6457 (1986). Amostras de solo - preparação para ensaios de compactação e ensaios de caracterização. Rio de Janeiro, Brasil.

ABNT: NBR 6459 (1984). Determinação do limite de liquidez. Rio de Janeiro, Brasil. ABNT: NBR 6508 (1984). Grãos que passam na peneira de 4,8 mm - Determinação da massa específica. Rio de Janeiro, Brasil.

ABNT: NBR 7180 (1984). Solo: Determinação do limite de plasticidade. Rio de Janeiro, Brasil.

ABNT: NBR 7181 (1984). Solo - Análise granulométrica - Método de ensaio. Rio de Janeiro, Brasil.

ABNT: NBR 7182 (1986). Solo - Ensaio de compactação. Rio de Janeiro, Brasil. ABNT: NBR 14545 (2000). Solo - Determinação do coeficiente de permeabilidade de solos argilosos a carga variável. Rio de Janeiro, Brasil

CARDOSO, L. S. P. (2011). Estudo do transporte de poluentes imiscíveis em solos.

Tese (Doutorado). Universidade Federal da Bahia, Salvador.

OLIVEIRA, J. C. S. (2001). Contaminação dos solos argilosos por líquidos orgânicos: problema de avaliação da permeabilidade. 205f. Tese (Doutorado em Geologia).

Instituto de Geociências, Universidade Federal da Bahia.

SOUSA, R. P (2012). Estudos dos fluxos de óleo diesel e água em solos não saturados: desenvolvimento experimental e modelagem matemática. Tese (Doutorado em Engenharia Industrial), Universidade Federal da Bahia, Salvador. 